Document downloaded from:

http://hdl.handle.net/10251/126156

This paper must be cited as:

Moreno Marro, O.; Atarés Huerta, LM.; Chiralt, A.; Cruz-Romero, MC.; Kerry, J. (2018). Starch-gelatin antimicrobial packaging materials to extend the shelf life of chicken breast fillets. LWT - Food Science and Technology. 97:483-490.

https://doi.org/10.1016/j.lwt.2018.07.005

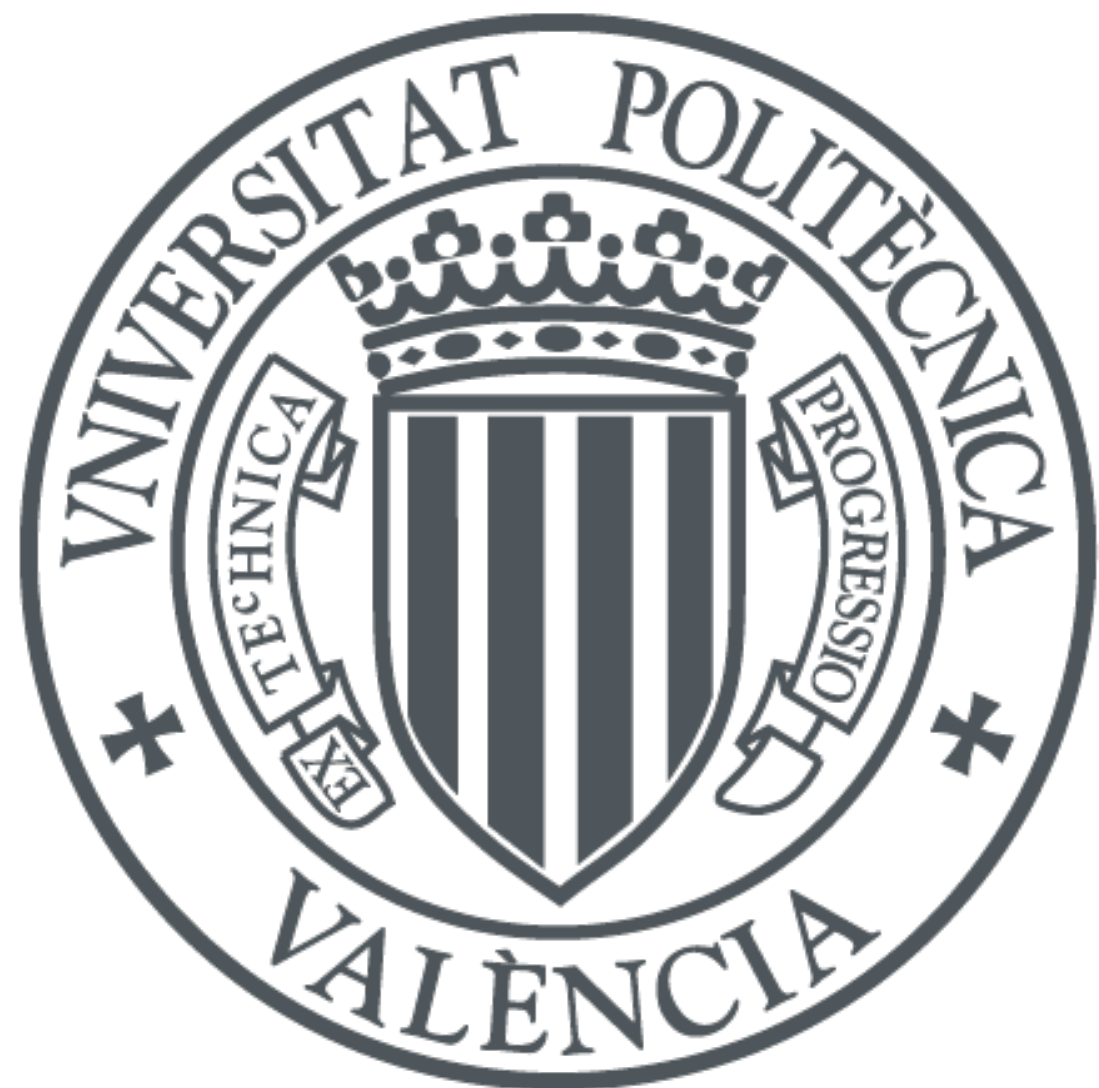

The final publication is available at

https://doi.org/10.1016/j.Iwt.2018.07.005

Copyright Elsevier

Additional Information 


\title{
STARCH-GELATIN ANTIMICROBIAL PACKAGING MATERIALS TO EXTEND THE SHELF LIFE OF CHICKEN BREAST FILLETS
}

\author{
Olga Moreno ${ }^{a *}$, Lorena Atarés ${ }^{a}$, Amparo Chiralt ${ }^{a}$, Malco C. Cruz-Romero ${ }^{b}$, Joseph \\ Kerry $^{b}$
}

a Departamento de Tecnología de Alimentos - Instituto de Ingeniería de Alimentos para el Desarrollo. Universitat Politècnica de València, Camino de Vera s/n 46022 Valencia, Spain

b Food Packaging Group, School of Food \& Nutritional Sciences, University College Cork, Cork,

Ireland

\section{Abstract}

Antimicrobial starch:gelatin (1:1) films containing $\mathrm{N}$-a-lauroyl--arginine ethyl ester monohydrochloride (LAE) (10 \% wt.) were used as food contact active layers in chicken breast fillets vacuum-packaged in polyamide/polyethylene pouches. Active layers were thermoprocessed (TP) or cast (OC) on the plastic film. Oxidized starch was used in OC coatings. Packaged chicken breast samples were stored at $4 \stackrel{\circ}{\circ} \mathrm{C}$ and their physicochemical properties ( $\mathrm{pH}$, colour and lipid oxidation) and microbial quality were analysed throughout storage. Both TP and OC films significantly $(p<0.05)$ extended the shelf life of chicken breast fillets compared to control samples. The starch oxidation reaction in OC films promoted the formation of Maillard reaction compounds in the starch-gelatine blends, which enhanced the antimicrobial effectiveness of the OC films, but also promoted oxidative processes. This greatly affected the $\mathrm{pH}$ and colour parameters in OC packaged samples. Therefore, TP blend films containing LAE are

*corresponding author: Olga Moreno. olgamm1587@gmail.com 
23 recommended since they effectively extended the shelf life of chicken breast fillets

24 without affecting the meat oxidation.

25 Keywords: LAE, starch, gelatin, antimicrobial, chicken breast

26 
Starch and gelatin has been extensively studied for the purposes of developing packaging materials because they are abundant, cheap and biodegradable materials, which are also edible and, thus, adequate for food contact purposes (Cazón, Velazquez, Ramírez \& Vázquez, 2017). Starch-gelatin (S-G) based films obtained by both casting or thermoprocessing methods exhibited good mechanical resistance and extensibility and low oxygen permeability (Acosta, Jiménez, Cháfer, González-Martínez, \& Chiralt, 2015; Moreno, Díaz, Atarés, \& Chiralt, 2016) and could be used for food packaging/coating uses. Nevertheless, the films are highly hydrophilic in nature and their properties are greatly affected by the water content. In this sense, starch oxidation through the hydroxyl groups in positions C-2 and C-3 of the anhydroglucose units, producing di-aldehyde starch (DAS) (Yu, Chang, \& Ma, 2010), have been used to reduce the hydrophilic nature of starch, while allows for binding amino groups (e.g. from proteins), producing a reinforced crosslinked matrix (Wang et al., 2015), with improved mechanical properties and water resistance. DAS is also suitable for food contact purposes and could be used for food packaging applications (Martucci \& Ruseckaite, 2009). Nevertheless, due to the lower thermo-stability of oxidized starch (Soliman, ElShinnawy, \& Mobarak, 1997), and the uncontrolled condensation reactions with the protein carbonyls at high temperature, thermoprocessing of oxidized starch-protein blends was not possible and casting methods would recommended to obtain DAS-G blend films or coatings.

S-G matrices could also be used as carriers of active compounds (e.g. antimicrobials) to obtain active films for food packaging applications. S-G matrices carrying antimicrobial compounds are suitable for food contact applications and could exert a controlled release of the antimicrobial towards the food surface. The application of antimicrobial packaging is especially interesting for the highly perishable meat products, where microbial contamination occurs primarily at the surface, due to post-processing handling 
54 (Quintavalla \& Vicini, 2002). Chicken meat is very popular in Europe, but it is highly perishable due to its characteristic composition, high water activity $\left(\mathrm{a}_{\mathrm{w}}\right)$ and a high $\mathrm{pH}$ (Rodríguez-Calleja, Cruz-Romero, O’Sullivan, García-López, \& Kerry, 2012). Then, the use of technologies, such as antimicrobial packaging, which can extend the shelf life of chicken breast fillets are very interesting for the poultry industry (Azlin-Hasim, CruzRomero, Morris, Cummins, \& Kerry, 2015).

Of the current antimicrobials, N-a-lauroyl-I-arginine ethyl ester monohydrochloride, (LAE), is a cationic surfactant considered as GRAS (Generally Recognized As Safe) by the FDA, and accepted for use in meat products in Europe (E243) (Hawkins, Rocabayera, Ruckman, Segret, \& Shaw, 2009; Higueras, López-Carballo, HernándezMuñoz, Gavara, \& Rollini, 2013). LAE has a wide spectrum of antimicrobial activity (Muriel-Galet, López-Carballo, Gavara, \& Hernández-Muñoz, 2015), even at low concentrations. Higueras et al. (2013) reported a minimally inhibitory concentration (MIC) of 16 and $8 \mu \mathrm{g} / \mathrm{mL}$ for Escherichia coli and Listeria monocytogenes, respectively. LAE increases the permeability of the cell membrane, as a consequence of a membrane protein denaturation, causing cell growth inhibition or death (Rodríguez, Seguer, Rocabayera, \& Manresa, 2004). This promising antimicrobial has been successfully applied on chicken (Higueras et al., 2013; Nair, Nannapaneni, Kiess, Mahmoud, \& Sharma, 2014); but, to the best of our knowledge, neither the use of S-G matrix as a carrier of this antimicrobial nor the application of the these antimicrobial films for the purposes of extending the shelf life of chicken fillets was reported.

The aim of this study was to assess the effectiveness of antimicrobial starch-gelatin films containing LAE at extending the shelf life of chicken breast fillets. Antimicrobial layers were obtained by either the thermoprocessing of non-oxidized starch-gelatin blends or the casting of oxidised starch-gelatin solutions. In both cases, food contact with the films was promoted through the vacuum packaging of samples in commercial polyethylene/polyamide laminates. 


\section{Materials and methods}

82

83

84

85

86

87

88

89

90

91

92

93

94

95

96

97

98

99

100

101

102

103

104

105

\subsection{Materials}

Film components: Corn starch (S) (Roquette Laisa España, S.A., Valencia, Spain); Bovine gelatin type A (G) (Sancho de Borja, S.L., Zaragoza, Spain); Sodium periodate (SP) (Fluka Analytical, Sigma-Aldrich Chemie GmbH, Steinheim, Germany); Ethyl lauroyl arginate (LAE) at $10 \% \mathrm{w} / \mathrm{v}$ in ethanol (Vedeqsa, Lamirsa, Terrassa, Spain) and glycerol (Panreac Química S.A., Castellar de Vallès, Barcelona, Spain). Magnesium nitrate was supplied by Panreac Química S.A. (Castellar del Vallés, Barcelona, Spain). Polyamide/low density polyethylene (PA/LDPE) pouches $(200 \times 300 \mathrm{~mm}$, water vapour transmission rate of $2.8 \mathrm{~g} / \mathrm{m}^{2} 24 \mathrm{~h}$ and oxygen permeability rate of $50 \mathrm{~cm}^{3} / \mathrm{m}^{2} 24 \mathrm{~h}$ ) were supplied by Cryovac (Sealed AirW.R. Grace Europe Inc., Lausanne, Switzerland).

The microbiological media (Maximum Recovery Diluent, Plate Count Agar (PCA), M RS Agar, Brilliance ${ }^{\mathrm{TM}}$ E.coli / Coliform Selective Medium), were supplied by Oxoid (Oxoid Ltd., Basingstoke, England). Tryptic Soy Agar and Yeast extract granulate were supplied by Merck (Merck KGaA, 64271 Darmstadt, Germany).

\subsection{Film preparation}

Thermo-processed starch-gelatin films

Two thermo-processed (TP) film formulations were obtained based on a S:G blend (wt. ratio 1:1). To prepare the control formulation (TP_C), the dry components were mixed, and glycerol and water added in a polymer:glycerol:water mass ratio of 1:0.3:1.1. For the antimicrobial active formulation (TP_LAE), LAE was also added, in a polymer: LAE mass ratio of 1:0.1. Each formulation was hot-blended at $160 \stackrel{\circ}{ } \mathrm{C}$ and $8 \mathrm{rpm}$ for 10 minutes on a two-roll mill (Model LRM-M-100, Labtech Engineering, Thailand). The pellets were conditioned at $53 \%$ relative humidity $(\mathrm{RH})$ for one week at $25{ }^{\circ} \mathrm{C}$ on a desiccator 
containing an oversaturated solution of $\mathrm{Mg}\left(\mathrm{NO}_{3}\right)_{2}$. The films were obtained by compression moulding using a hot-plate press (Model LP20, Labtech Engineering, Thailand). Four grams of the conditioned pellets were pre-heated for $5 \mathrm{~min}$ at $160{ }^{\circ} \mathrm{C}$ in the press plate and then pressed at $3000 \mathrm{KPa}$ for $2 \mathrm{~min}$ and $13000 \mathrm{KPa}$ pressure for 6 $\min$ at $160 \stackrel{\circ}{\circ}$. Thereafter, a cooling cycle to $6{ }^{\circ} \mathrm{C}$ was applied for $3 \mathrm{~min}$. The obtained films were $17 \mathrm{~cm}$ in diameter and $180 \pm 0.014 \mu \mathrm{m}$ thick.

\section{Coated packaging with oxidized starch-gelatin blends}

The corn starch was oxidized following the method described by Yu et al. (2010), using SP as oxidizing agent, with some modifications. Briefly, a $10 \%(w / v)$ of $S$ was dispersed in distilled water while gently stirred. SP was added in a molar ratio SP:Glucose unit of 1:1. The dispersion obtained was kept in the dark for four hours, under controlled conditions ( $35^{\circ} \mathrm{C}$ and $\mathrm{pH}$ 3.5). The oxidized starch (OS) was vacuum filtered (Vacuum / Pressure Station, Barnant Company, Barrington, Illinois, United States) and washed three times with distilled water to ensure the complete elimination of the reagent. The oxidised starch was re-dispersed in water at $8000 \mathrm{rpm}$ for 30 seconds using an ultraturrax (DI25, Janke andKunkel, Germany)) and vacuum filtered. The obtained wet solids were used for film preparation, taking into account the water content, previously determined gravimetrically.

OS (6\% wt.) was dispersed in distilled water and gelatinized at $99{ }^{\circ} \mathrm{C}$ in a thermostatic water bath (SW23, Julabo GmbH, 77960 Seelbach/ Germany) for $1 \mathrm{~h}$ under gentle agitation at $100 \mathrm{rpm}$. A $6 \%$ wt. dispersion of $\mathrm{G}$ was also prepared at $40{ }^{\circ} \mathrm{C}$ while being stirred at $450 \mathrm{rpm}$ in a hot-plate for $30 \mathrm{~min}$. Then, both dispersions were cooled down to room temperature and blended in a 1:1. mass ratio and glycerol was added at $25 \% \mathrm{w} / \mathrm{w}$ of the total polymer mass (OC_C, control formulation). For the active formulation (OC_LAE), LAE was added in a polymer:LAE ratio of 1:0.1. All of the solutions were kept 
under constant stirring for $30 \mathrm{~min}$ at $450 \mathrm{rpm}$ until casting. Casting was carried out on a levelled inner polyethylene layer of PA/LDPE laminates using a Micron II film applicator (Gardco, FL, USA) and dried for $48 \mathrm{~h}$ at $20{ }^{\circ} \mathrm{C}$. The solid density on the surface of the PA/LDPE films was $840 \mathrm{~g}$ dry solids $/ \mathrm{m}^{2}$. To obtain pouches $(102 \times 177 \mathrm{~mm})$, the edges of the films were heat-sealed using a Henkelman Polar 80 (Henkelman Vacuum System, Model Polar 80, 5221 CK 's-Hertogenbosch, The Netherlands) with a sealing time of 2.5 s.

\subsection{Chicken sample preparation and experimental Design}

Fresh chicken breast fillets were purchased from a local supplier (Shannon Vale Foods Ltd. Clonakilty, Co. Cork, Ireland), kept in a chill room at $2{ }^{\circ} \mathrm{C}$ and used within $24 \mathrm{~h}$. To avoid cross contamination during sample preparation, all utensils and work surfaces were sanitized with $70 \%$ ethanol and the TP and OC films were decontaminated by exposure to UV light for $15 \mathrm{~min}$ in a laminar flow (Airclean 600 PCR Workstation STARLAB, Airclean Systems, USA). Excess fat and cartilage were trimmed from the chicken breast fillets and immediately packaged using either control (TP_C or OC_C) or active (TP_LAE or OC_LAE) films with LAE. Chicken breast fillets $(150-180 \mathrm{~g}, 1 \mathrm{~cm}$ of thickness) were individually wrapped in the sterilised TP films and placed individually into PA/LDPE pouches, or packaged in the coated PA/LDPE pouches. Afterwards, all pouches were vacuum sealed using a Henkelman Polar 80 vacuum system and stored at $4{ }^{\circ} \mathrm{C}$ for 19 days. Three independent experimental series, with different reception days, were run for both TP and OC packaged samples. Three fresh chicken samples were vacuum packaged in the conventional PA/LDPE pouches for the initial characterization of the raw material (chicken control). All samples were kept packaged under refrigerated conditions $\left(4^{\circ} \mathrm{C}\right)$ throughout different storage times until 19 days and three samples from 
157

each series (different packaging conditions) were analysed at 0 ( $2 \mathrm{~h}$ contact time) 2, 6 , 9,12 and 19 days.

\subsection{Physicochemical characterization}

Proximal analysis

The proximal composition (fat, moisture, protein and ash) of the chicken control and packaged samples was determined after 2 hours of contact with the packaging.

Fat and moisture contents were determined using the CEM Analysis System (CEM Corporation, Matthews, NC 28105, USA) as described by Bostian, Fish, Webb, \& Arey, (1985). Protein content was determined using the Kjeldahl Method, following AOAC Procedures (1999) (method 981.10). Finally, the ash content was obtained by a gravimetric method, weighing the samples before and after incineration in a furnace (Nabertherm, Model L9/C6, Nabertherm, Germany) at $550{ }^{\circ} \mathrm{C}$. All the tests were run in duplicate for each series, and the reported values are the average of 6 replicates.

\section{Determination of $\mathrm{pH}$, lipid oxidation and colour}

Throughout storage, the $\mathrm{pH}$, lipid oxidation and colour changes in the packaged chicken breast fillets were monitored. For day 0 , the reported values correspond to $2 \mathrm{~h}$ contact with the films. The $\mathrm{pH}$ was measured using a digital $\mathrm{pH}$ meter by direct insertion of the glass electrode probe into the fillet (Mettler-Toledo GmbH, Schwerzenbach, Switzerland). Four measurements were taken per each sample (12 replicates). 
180 The lipid oxidation was assessed using the method described by Siu \& Draper (1978).

181 The results were expressed as $\mathrm{mg}$ of malondialdehyde (MDA)/kg of sample (6 182 replicates).

183 Once the films were removed, the colour (CIE $L^{*} a^{*} b^{*}$ colour coordinates) of the fillets was measured using D65 illuminant $/ 10^{\circ}$ observer, at ten random points on the sample surface, using a portable Minolta CR-300 colorimeter (Minolta Camera Co., Osaka, Japan), previously calibrated with a white ceramic plate $(Y=93.6, x=0.3130, y=$ 0.3193). The total colour difference with respect to the fresh chicken throughout chilled storage was calculated using Equation 1. The reported value is the average of 30 replicates.

$$
\Delta E=\sqrt{\left(\Delta L^{*}\right)^{2}+\left(\Delta a^{*}\right)^{2}+\left(\Delta b^{*}\right)^{2}}
$$

Equation 1

\subsection{Microbiological analysis}

Microbiological analysis of the packaged chicken breast fillets was carried out at the different storage times. A total of $10 \mathrm{~g}$ of meat sample was aseptically taken from both the upper and bottom surface of the chicken breast fillets using sterile forceps and scalpels, placed into a sterile stomacher filter bag (Seward, UK) to which $90 \mathrm{~mL}$ of sterile Maximum recovery diluent (MRD) (Oxoid, UK) was added and thoroughly mixed for 3 min using a stomacher (Seward, UK) in order to obtain a primary 10-fold dilution. This homogenate was then 10-fold serially diluted using MRD and used to enumerate total viable counts (TVC), psychrotrophic bacteria (PB), Lactic acid bacteria (LAB), anaerobic bacteria (AB), total coliforms (TC) and Escherichia coli (E. coli). TVC and PB were enumerated in PCA plates, after incubation at $37^{\circ} \mathrm{C}$ or $4^{\circ} \mathrm{C}$ for $48 \mathrm{~h}$ or 7 days, respectively. $\mathrm{LAB}$ was enumerated using overlaid MRS agar plates after incubation at $30 \stackrel{\circ}{\mathrm{C}}$ for $72 \mathrm{~h}$. Enumeration of $\mathrm{AB}$ was performed in TSA enriched with $0.6 \%$ yeast extract after $72 \mathrm{~h}$ incubation at $30 \stackrel{\circ}{\circ}$ under anaerobic conditions in an anaerobic jar 
containing Anaerocult $\AA$. Finally, TC and E. coli were enumerated in the chromogenic medium Brilliance E.coli/Coliforms Selective Agar after incubation at $37^{\circ} \mathrm{C}$ for $24 \mathrm{~h}$. The results of bacterial counts were converted to $\log _{10}$ colony-forming units per gram of sample (log CFU/g) prior to statistical analyses.

\subsection{Statistical analysis}

Analysis of variance was performed using general linear models, considering the effect of the following factors: time, packaging treatment, chicken trial (random factor) and the interaction time * packaging treatment. These tests were carried out, using Statgraphics Centurion XVI (Manugistics Corp., Rockville, MD). Fisher's least significant difference (LSD) at the $95 \%$ confidence level was used to compare treatments.

\section{Results and discussion}

\subsection{Physicochemical characteristics of initial chicken breasts.}

\section{Proximal composition}

All of the chicken samples exhibited a similar proximal composition (Table 1), in the range of that previously reported for these kinds of samples (Azlin-Hasim et al., 2015). The small variations could be attributed to commercial breeds, diet formulation, housing and general management practices (Qiao, Fletcher, Northcutt, \& Smith, 2002). Contact with both TP films significantly decreased the moisture content in the chicken samples, which can be attributed to the high water absorption capacity by the films. Moreno et al. (2016) reported a water uptake capacity of $600 \mathrm{~g}$ water/g dry film for these films, whereas OC films showed lower water uptake (100-300 g water/g dry film), due to their reduced 
hydrophilic nature (Yu et al., 2010). Likewise, the protein content of samples packaged in TP films was significantly $(p<0.05)$ higher, which mainly resulted from their reduced moisture content.

\section{Colour, $\mathrm{pH}$ and lipid oxidation}

Table 2 shows the colour coordinates of fillets after two hours in contact with the packaging. Significant differences $(p<0.05)$ in the sample lightness $\left(L^{*}\right)$, redness $\left(a^{*}\right)$ and yellowness $\left(b^{*}\right)$ were observed for the fillets packaged in TP films. These samples became slightly darker, with small chromatic changes, which may be attributed to the significant reduction in the moisture content, which mainly occurred at the surface in contact with the TP films (more hydrophilic than OC film), where colour was measured. Water loss leads to changes in the selective light reflection at the sample surface, due to the changes in the refractive index of the material and the surface concentration of the pigments (Hutchings, 1999). However, the sample colour is in the range of that reported (Huang, Williams, Sims, \& Simmone, 2011) considering the natural variability of the product by genetics and other factors (Lonergan, Deeb, Fedler, \& Lamont, 2003).

The $\mathrm{pH}$ of the fillets ranged between 5.86 and 6.16 , which is considered a typical $\mathrm{pH}$ value for poultry meat (Barbut, Zhang, \& Marcone, 2005; Huang et al., 2011; RodríguezCalleja et al., 2012; Qiao et al., 2002). However, samples in contact with OC_C films exhibited a significantly $(\mathrm{p}<0.05)$ lower $\mathrm{pH}$-value (nearer of the OC_LAE sample), as compared with the more homogenous $\mathrm{pH}$ of the rest of the samples.

Lipid oxidation, one of the main factors causing flavour deterioration during the storage of meat and meat products (Azlin-Hasim et al., 2015; Rodríguez-Calleja et al., 2012) was evaluated through the TBARS assay, which provides an indicator of the secondary oxidation. The analyses of the initial samples (Table 2) showed low MDA levels, ranging between 0.05 and $0.33 \mathrm{mg} \mathrm{MDA} / \mathrm{kg}$ of sample, which are typical values for fresh chicken 
meat (Azlin-Hasim et al., 2015; Rodríguez-Calleja et al., 2012). Nevertheless, samples packaged with the starch films showed significantly $(p<0.05)$ higher TBARS values, especially those in contact with the oxidized starch coatings.

\section{Microbial counts}

The initial microbial counts of the samples are shown in Table 3. The TVC counts of the all samples (3-5 log CFU/g) indicated the good microbiological quality of the chicken meat (Azlin-Hasim et al., 2015). Similar initial TVC and PB counts were previously reported for these kinds of products (Azlin-Hasim et al., 2015; Balamatsia, Paleologos, Kontominas, \& Savvaidis, 2006; Rodríguez-Calleja et al., 2012), although slightly higher LAB counts were obtained. Significantly lower $(p<0.05)$ counts of all bacteria, except Coliforms, were observed for fillets packaged in the OC_LAE system, where E. coli was not detected. In general, counts of the different bacteria were lower for samples packaged in films containing LAE, which indicates the fast action of this antimicrobial on the bacteria population.

\subsection{Physicochemical changes during chilled storage}

\section{Lipid oxidation}

Development of lipid oxidation during the chilled storage of the fillets are shown in Figure 1a for the different packaging systems. Samples wrapped in TP films exhibited very slow lipid oxidation throughout storage, whereas samples in contact with OC films exhibited a significant $(p<0.05)$ increase in the TBARS values. This increase $(p<0.05)$ in the lipid oxidation of the OC coated chicken samples, may be due to the presence of oxidant species formed during the oxidation process of starch, which can promote lipid oxidation in the fillets. In fact, Maillard reaction compounds produced in OC films due to the 
carbonyl-amino condensation reaction (Moreno, Gil, Atarés, \& Chiralt, 2017), generate hydrogen peroxide $\left(\mathrm{H}_{2} \mathrm{O}_{2}\right)$, which confer them antimicrobial action (Hauser, Müller, Sauer, Augner, \& Pischetsrieder, 2014). Samples packaged in OC_LAE films, underwent significantly greater $(p<0.05)$ lipid oxidation, suggesting a greater formation of Maillard compounds and oxidant species when LAE was present in the films, probably due to the presence of more reactive amino groups of this low molecular weight compound.

Melton (1983) reported that a TBARS value of $1.5 \mathrm{mg} \mathrm{MDA} / \mathrm{kg}$ is regarded as the limit beyond which chicken meat will normally develop objectionable odours/tastes. This limit of acceptability in terms of TBARS was reached after 9 and 19 storage days in samples packaged in OC_LAE and OC_C films, respectively. In contrast, the samples packaged in TP films did not show significant differences in TBARS values, with respect to the fresh chicken, throughout 19 days of chilled storage.

\section{$\mathrm{pH}$ and Colour}

Figure $1 \mathrm{~b}$ and Figure 2 show the changes in the $\mathrm{pH}$ and colour of the fillets, respectively, during the storage in the different packaging systems. The initial $\mathrm{pH}$ values of the samples packaged in the different film formulations ranged between 5.86 and 6.16 . This range shows the variability expected for the raw material and, considering the fact that different samples are analysed at each control time, only for samples packaged in films with oxidized starch containing $\mathrm{LAE}$, the $\mathrm{pH}$ value significantly decreased below the lower limit at the longest storage time. The $\mathrm{pH}$ development in the chicken samples will be affected by microbial growth and the oxidation process, which occurred to a different extent in OC and TP packaged fillets. The different population of bacteria and the subsequent lactic acid production or volatile amine and ammonia generation can alter the sample pH promoting the sample differences (Azlin-Hasim et al., 2015; Cortez-Vega, Pizato, \& Prentice, 2012). Likewise, lipid oxidation is also associated with protein 
oxidation, which increases the number of carboxyl groups and decreases that of sulfhydryl groups (Soyer, Özalp, Dalmış, \& Bilgin, 2010). Therefore, the significantly $(p<0.05)$ higher oxidation level of the OC_LAE packaged fillets during storage could be associated their lower $\mathrm{pH}$. In samples packaged with $\mathrm{OC}$ films, the $\mathrm{pH}$ could be more affected by the progress of the oxidation process, since they had lower microbial counts, whereas for samples in TP systems the $\mathrm{pH}$ would mainly governed by the action of bacteria that grow to a greater extent.

Figure 2 shows the changes in the $L^{*}, a^{*}$ and $b^{*}$ values of fillets during chilled storage at $4 \stackrel{\circ}{ }{ }^{\circ}$. $L^{*}$ values increased during storage in the samples, indicating that the fillets became paler. This could be due to the generalised $\mathrm{pH}$ decrease in the samples throughout storage time. Previous studies reported that the $\mathrm{pH}$ significantly affects the lightness of meat products (Barbut et al., 2005; Lonergan et al., 2003; Qiao et al., 2002). Low pH can lead to protein solubilisation and denaturation and a paler meat. The sample redness ( $\mathrm{a}^{*}$ values) was significantly $(p<0.05)$ lower for those packaged in films containing LAE, throughout the storage time. This suggests that LAE could interact with the meat pigments, thus affecting redness. In contrast, the sample yellowness ( $b^{*}$ values) increased to a greater extent in fillets packaged in OC films. This significantly $(p<0.05)$ higher yellowness values could be related with the greater progression of lipid oxidation. In fact, samples packaged in OC_LAE films (Figure 2c) exhibited the highest oxidation levels and the lowest $\mathrm{pH}$ (Figure 1) at the end of storage. Figure $2 \mathrm{~d}$ shows the total colour difference quantified for the packaged samples throughout chilled storage at $4{ }^{\circ} \mathrm{C}$ with respect to the initial fresh chicken. $\mathrm{A} \Delta \mathrm{E}$ value of 1.5 was quantified between the different fresh samples, which is at the limit of the visual perception of colour difference $(\Delta \mathrm{E} \sim 1$ in the CIEL ${ }^{*} a^{*} b^{*}$ space; Hutchings, 1999). Most of the packaged samples exhibited colour differences with respect to fresh chicken of under 5 , which correspond to a reasonable tolerance as regards the colour difference in food products (Hutchings, 1999). The samples that were newly packaged in TP systems showed greater $\Delta \mathrm{E}$ values due to their 
surface dehydration, as commented on above, but this difference was mitigated throughout storage in line with the progressive water diffusion from the inner part of the breast. After 19 storage days, the samples packaged in the OC_LAE system also exceeded $5 \Delta \mathrm{E}$ units, which is attributable to the great oxidation progress and the $\mathrm{pH}$ associated change. Therefore, only samples packaged in the OC_LAE system exhibited an unacceptable colour change after 19 storage days, while they also presented excessive oxidation levels.

\section{Microbial growth}

The microbial quality of poultry meat is used as an indicator of freshness, since the growth of spoilage microorganisms can cause the development of unacceptable offodours and off-flavours (Balamatsia et al., 2006). The recommended limits of acceptability for raw chicken are: $m=10^{6} \mathrm{CFU} / \mathrm{g}$ for aerobic plate counts (acceptable limit) and $M=10^{7} \mathrm{CFU} / \mathrm{g}$ (unacceptable limit) (EC, 2007). Thus, a value of 6 log $\mathrm{CFU} / \mathrm{g}$ of meat for TVC was set as the maximum limit of acceptability.

Changes in the microbial counts of TVC, PB, LAB, AB and total coliforms in the samples are shown in Figure 3. Regardless of the packaging system, the PB counts were the highest, being the main spoilage microorganism, according to that reported for chilled meat (Murphy, O'Grady, \& Kerry, 2013). LAB counts were also higher than the TVC counts and $A B$ exhibited a similar behaviour, although the low $\mathrm{O}_{2}$ concentration in the package could favour their growth (Rodríguez-Calleja et al., 2012). The initial counts of E. coli were below the detection limit $(<1 \log$ CFU/g) (data not shown) and a slight increase in the E. coli counts was noticed during the storage period in samples packaged in the LAE free films, reaching a level of $2.1 \mathrm{log} C F U / g$ at the end of storage. TP_LAE or OC_LAE films were effective at maintaining the numerical presence of $E$. coli below the 
detection limit, indicating the effectiveness of LAE as an antimicrobial with which to preserve chicken breast fillets.

The counts of all bacteria increased during storage, but samples packaged in films containing LAE (TP_LAE or OC_LAE) exhibited a delayed bacteria growth. Likewise, lower counts were found in samples packaged in OC LAE-free films when compared to those coated by LAE-free TP films. This difference in the fillet bacterial load reflect the antimicrobial action of the Maillard compounds formed in the OC films, as previously reported by Moreno et al. (2017) for marinated salmon samples packaged in similar films. The greatest effects were observed in TVC and LAB. Similarly, OC_LAE films were more effective than TP_LAE films at delaying the growth of most bacteria, which also points to a combined effect of LAE and the Maillard compounds in the OC films. Moreno et al. (2017) reported antilisterial activity for oxidized starch-gelatine films with and without $\mathrm{LAE}$, while they extend the self-life of marinated salmon in terms of microbial growth.

Therefore, in terms of microbial growth, the use of films containing LAE significantly extended the shelf life of chicken breast filets. The limit of microbial acceptability (6 log CFU/g) for TVC was reached after 12 days for samples packaged in the control TP_C films, whereas this limit was reached after 16 days for fillets packaged in TP_LAE or OC_C films and it was not reached throughout the 19 storage days in fillets in contact with OC_LAE films. It is remarkable that the antimicrobial effect of LAE was more effective in OC films than in TP films due to the combined action of the active compounds. However, the shelf life of chicken samples packaged in OC_LAE was limited by lipid oxidation, as previously commented on.

It is remarkable that OC_LAE films seem to lose effectiveness after 6 storage days when the cell growth resumed in the samples. This may be due to the partial recovery and growth of the bacteria in response to the stress induced by the antimicrobial compounds. Nevertheless, a slower growth was also observed after 13 storage days. Likewise, the 
obtained results indicated that LAB (Gram positive bacteria) were more sensitive to the antimicrobial action of LAE than total coliforms (Gram negative bacteria), which agrees with that reported in previous studies (Higueras et al., 2013; Muriel-Galet et al., 2015).

\section{Conclusions}

Films of S-G containing LAE greatly enhanced the shelf life of chicken breast fillets. The microbiological limit of acceptability for TVC was reached after 16 or 12 storage days for fillets packaged in TP films containing or not LAE, respectively, which represented a notable increase in the shelf life of the fillets. Those films containing oxidised starch (OC) without LAE, also extended the microbiological shelf life of the fillets by 4 days while OC_LAE films were the most effective at controlling microbial growth, but the presence of pro-oxidant compounds in OC films promoted lipid oxidation, which, in turn, affected the sample colour. Therefore, in samples packaged in OC films, the critical parameter to define the shelf life of the chicken breast fillets was the lipid oxidation and they are not recommended as packaging material of oxidation-sensitive foodstuffs. Starch-gelatin TP films containing LAE have the potential to be used as antimicrobial packaging material in order to increase the shelf life of chicken breast fillets.

\section{Acknowledgements}

The authors acknowledge the financial support provided by Ministerio de Economía y Competividad (Projects AGL2016-76699-R and AGL2013-42989-R). Olga Moreno Marro also thanks the Ministerio de Educación, Cultura y Deporte for the FPU 2012-1121 grant. 


\section{REFERENCES}

415

416

417

418

419

420

421

422

423

424

425

426

427

428

429

430

431

Acosta, S., Jiménez, A., Cháfer, M., González-Martínez, C., \& Chiralt, A. (2015) Physical properties and stability of starch-gelatin based films as affected by the addition of esters of fatty acids. Food Hydrocolloids, 49, 135-143.

AOAC. (1999). Official methods of analysis of AOAC international. P., Cunniff, 16th edition, 5th revision. Maryland: AOAC International.

Azlin-Hasim, S., Cruz-Romero, M. C., Morris, M. A., Cummins, E., \& Kerry, J. P. (2015).

Effects of a combination of antimicrobial silver low density polyethylene nanocomposite films and modified atmosphere packaging on the shelf life of chicken breast fillets. Food Packaging and Shelf Life, 4, 26-35.

Balamatsia, C. C., Paleologos, E. K., Kontominas, M. G., \& Savvaidis, I. N. (2006). Correlation between microbial flora, sensory changes and biogenic amines formation in fresh chicken meat stored aerobically or under modified atmosphere packaging at $4 \mathrm{C}$ : possible role of biogenic amines as spoilage indicators. Antonie van Leeuwenhoek, 89(1), 9-17.

Barbut, S., Zhang, L., \& Marcone, M. (2005). Effects of pale, normal, and dark chicken breast meat on microstructure, extractable proteins, and cooking of marinated fillets. Poultry Science, 84, 797-802. 
432 Bostian, M. L., Fish, D. L., Webb, N. B., \& Arey, J. J. (1985). Automated methods for 433 determination of fat and moisture in meat and poultry products: Collaborative study. 434 Journal of the Association of Official Analytical Chemists, 68(5), 876-880.

435 Cazón, P., Velazquez, G., Ramírez, J. A., \& Vázquez, M. (2017). Polysaccharide-based 436 films and coatings for food packaging: A review. Food Hydrocolloids, 68, 136-148.

437 Cortez-Vega, W. R., Pizato, S., \& Prentice, C. (2012). Quality of raw chicken breast 438 stored at $5{ }^{\circ} \mathrm{C}$ and packaged under different modified atmospheres. Journal of Food 439 Safety, 32(3), 360-368.

440 EC (2007). Commission Regulation No 1441/2007 of 5 December 2007 amending 441 Regulation (EC) No 2073/2005 on microbiological criteria for foodstuffs.

442 Hauser, C., Müller, U., Sauer, T., Augner, K., \& Pischetsrieder, M. (2014). Maillard reaction products as antimicrobial components for packaging films. Food chemistry, 145, 603-613.

Hawkins, D.R., Rocabayera, X., Ruckman, S., Segret, R., \& Shaw, D. (2009). Metabolism and pharmacokinetics of ethyl Na-lauroyl-L-arginate hydrochloride in human volunteers. Food and Chemical Toxicology, 47, 2711-2715.

Higueras, L., López-Carballo, G., Hernández-Muñoz, P., Gavara, R., \& Rollini, M. (2013). Development of a novel antimicrobial film based on chitosan with LAE (ethyl-Nadodecanoyl-L-arginate) and its application to fresh chicken. International Journal of Food Microbiology, 165, 339-345.

Huang, H., Williams, S. K., Sims, C. A., \& Simmone, A. (2011). Sodium metasilicate affects antimicrobial, sensory, physical, and chemical characteristics of fresh commercial chicken breast meat stored at $4 \mathrm{C}$ for 9 days. Poultry Science, 90(5), 1124-1133. 237 pp). Springer US. 
457 Lonergan, S. M., Deeb, N., Fedler, C. A., \& Lamont, S. J. (2003). Breast meat quality 458 and composition in unique chicken populations. Poultry Science, 82(12), 1990-1994.

459 Martucci, J. F., \& Ruseckaite, R. A. (2009). Tensile properties, barrier properties, and 460 biodegradation in soil of compression-Molded gelatin-dialdehyde starch films. Journal 461 of Applied Polymer Science, 112(4), 2166-2178.

Melton, S. L. (1983). Methodology for following lipid oxidation in muscle foods. Food 463 Technology, 37, 105-I 11.

Moreno, O., Díaz, R., Atarés, L., \& Chiralt, A. (2016). Influence of the processing method 465 and antimicrobial agents on properties of starch-gelatin biodegradable films. Polymer 466 International, 65(8), 905-914.

Moreno, O., Gil, À., Atarés, L., \& Chiralt, A. (2017). Active starch-gelatin films for shelf468 life extension of marinated salmon. LWT-Food Science and Technology, 84, 189-195.

Muriel-Galet, V., Lopez-Carballo, G., Gavara, R., \& Hernández-Muñoz, P. (2015). Antimicrobial effectiveness of lauroyl arginate incorporated into ethylene vinyl alcohol copolymers to extend the shelf-life of chicken stock and surimi sticks. Food and Bioprocess Technology, 8(1), 208-217.

Murphy, K. M., O'Grady, M. N., \& Kerry, J. P. (2013). Effect of varying the gas headspace to meat ratio on the quality and shelf-life of beef steaks packaged in high oxygen modified atmosphere packs. Meat Science, 94(4), 447-454.

Nair, D. V., Nannapaneni, R., Kiess, A., Mahmoud, B., \& Sharma, C. S. (2014). Antimicrobial efficacy of lauric arginate against Campylobacter jejuni and spoilage organisms on chicken breast fillets. Poultry Science, 93(10), 2636-2640. raw broiler breast meat color and composition. Poultry Science, 81(3), 422-427. 
481 Quintavalla, S., \& Vicini, L. (2002). Antimicrobial food packaging in meat industry. Meat 482 science, 62(3), 373-380.

483 Rodríguez, E., Seguer, J., Rocabayera, X., \& Manresa., A. (2004). Cellular effects of 484 monohydrochloride of L-arginine, Na-lauroyl ethylester (LAE) on exposure to Salmonella 485 typhimurium and Staphylococcus aureus. Journal of Applied Microbiology. 96, 903-912.

486 Rodríguez-Calleja, J. M., Cruz-Romero, M. C., O’Sullivan, M. G., García-López, M. L., \& 487 Kerry, J. P. (2012). High-pressure-based hurdle strategy to extend the shelf-life of fresh 488 chicken breast fillets. Food Control, 25(2), 516-524.

489 Siu, G. M., \& Draper, H. H. (1978). A survey of malonaldehyde content of retail meats 490 and fish. Journal of Food Science, 43, 1147-1149.

491 Soliman, A. A., El-Shinnawy, N. A., \& Mobarak, F. (1997). Thermal behaviour of starch 492 and oxidized starch. Thermochimica Acta, 296(1), 149-153.

Soyer, A., Özalp, B., Dalmış, Ü., \& Bilgin, V. (2010). Effects of freezing temperature and 494 duration of frozen storage on lipid and protein oxidation in chicken meat. Food 495 Chemistry, 120(4), 1025-1030.

496 Wang, X., Gu, Z., Qin, H., Li, L., Yang, X., \& Yu, X. (2015). Crosslinking effect of 497 dialdehyde starch (DAS) on decellularized porcine aortas for tissue engineering. International Journal of Biological Macromolecules, 79, 813-821. starch and thermoplastic dialdehyde starch. Carbohydrate Polymers, 79(2), 296-300. 
502 Table 1 Composition of the breast samples of both fresh control chicken and after two

503 hours of contact with the packaging*.

\begin{tabular}{lcccc}
\hline \multicolumn{1}{c}{ Sample } & Moisture \% & Fat \% & Protein \% & Ashes \% \\
\hline Control Chicken & $73.74 \pm 0.04^{\mathrm{b}}$ & $2.59 \pm 0.08^{\mathrm{ab}}$ & $23.7 \pm 0.3^{\mathrm{ab}}$ & $1.26 \pm 0.04^{\mathrm{a}}$ \\
\hline OC_C & $73.5 \pm 0.6^{\mathrm{b}}$ & $2.4 \pm 0.7^{\mathrm{a}}$ & $23.7 \pm 0.3^{\mathrm{a}}$ & $1.24 \pm 0.06^{\mathrm{a}}$ \\
\hline OC_LAE & $73.0 \pm 0.5^{\mathrm{b}}$ & $3.1 \pm 0.3^{\mathrm{b}}$ & $23.4 \pm 0.5^{\mathrm{a}}$ & $1.24 \pm 0.05^{\mathrm{a}}$ \\
\hline TP_C & $72.1 \pm 0.7^{\mathrm{a}}$ & $3.15 \pm 0.10^{\mathrm{b}}$ & $24.9 \pm 1.3^{\mathrm{b}}$ & $1.25 \pm 0.02^{\mathrm{a}}$ \\
\hline TP_LAE & $71.8 \pm 0.9^{\mathrm{a}}$ & $3.2 \pm 0.6^{\mathrm{b}}$ & $24.7 \pm 0.7^{\mathrm{b}}$ & $1.24 \pm 0.03^{\mathrm{a}}$ \\
\hline
\end{tabular}

$504{ }^{*}$ All values are means \pm standard deviations of duplicate data from three independent experiments $(n=6)$.

505 OC: oxidized starch coating; TP: thermo-processed.

$506 \quad a, b$ Different superscripts letters in the same column indicate significant differences $(p<0.05)$

507 
508 Table 2 Values determined for CIE Lab* coordinates ( $L^{*}$, lightness; $a^{*}$, redness; $b^{*}$, 509 yellowness), lipid oxidation expressed as $\mathrm{mg}$ of MDA / $\mathrm{kg}$ of sample, and $\mathrm{pH}$, for fresh

510 chicken and samples after two hours in contact with the different packaging systems*

\begin{tabular}{lccccc}
\hline \multicolumn{1}{c}{ Sample } & $\mathbf{L}^{*}$ & $\mathbf{a}^{*}$ & $\mathbf{b}^{*}$ & pH & $\begin{array}{c}\text { TBARS } \\
\text { (mg MDA/kg sample) }\end{array}$ \\
\hline Chicken control & $56 \pm 3^{\mathrm{C}}$ & $1.29 \pm 0.14^{\mathrm{a}}$ & $6.4 \pm 1.9^{\mathrm{c}}$ & $6.07 \pm 0.09^{\mathrm{bc}}$ & $0.05 \pm 0.03^{\mathrm{a}}$ \\
OC_C & $55 \pm 2^{\mathrm{bc}}$ & $2.7 \pm 1.3^{\mathrm{C}}$ & $5.3 \pm 1.8^{\mathrm{b}}$ & $5.86 \pm 0.19^{\mathrm{a}}$ & $0.27 \pm 0.06^{\mathrm{cd}}$ \\
\hline OC_LAE & $55 \pm 2^{\mathrm{b}}$ & $1.6 \pm 0.9^{\mathrm{ab}}$ & $5.3 \pm 1.8^{\mathrm{b}}$ & $6.00 \pm 0.17^{\mathrm{b}}$ & $0.33 \pm 0.09^{\mathrm{d}}$ \\
TP_C & $50 \pm 2^{\mathrm{a}}$ & $2.0 \pm 0.6^{\mathrm{b}}$ & $5.7 \pm 1.3^{\mathrm{bc}}$ & $6.10 \pm 0.11^{\mathrm{bc}}$ & $0.17 \pm 0.07^{\mathrm{b}}$ \\
\hline TP_LAE & $50 \pm 2^{\mathrm{a}}$ & $1.8 \pm 1.1^{\mathrm{ab}}$ & $4.4 \pm 1.0^{\mathrm{a}}$ & $6.16 \pm 0.09^{\mathrm{c}}$ & $0.19 \pm 0.12^{\mathrm{bc}}$ \\
\hline
\end{tabular}

$511{ }^{*}$ All values are means \pm standard deviations of duplicate data from three independent experiments $(n=6)$.

512 OC: oxidized starch coating; TP: thermo-processed.

$513 a, b, c, d$ Different superscripts letters in the same column indicate significant differences $(p<0.05)$. 
515 Table 3 Microbial counts for TVC, PB, LAB, AB, Coliforms and E.coli of the fresh chicken

516 breasts and samples after two hours in contact with the different packaging system.

517 Results expressed as log CFU/g of sample.

\begin{tabular}{lcccccc}
\hline \multicolumn{1}{c}{ Sample } & TVC & PB & LAB & AB & Coliforms & E. coli \\
\hline Chicken control & $4.3 \pm 0.3^{\mathrm{b}}$ & $5.1 \pm 0.1^{\mathrm{bc}}$ & $4.2 \pm 0.4^{\mathrm{bc}}$ & $4.6 \pm 0.4^{\mathrm{bc}}$ & $2.0 \pm 0.3^{\mathrm{ab}}$ & $1.49 \pm 0.16^{\mathrm{a}}$ \\
\hline OC_C & $4.2 \pm 0.3^{\mathrm{b}}$ & $5.0 \pm 0.3^{\mathrm{bc}}$ & $4.3 \pm 1.2^{\mathrm{c}}$ & $4.8 \pm 0.8^{\mathrm{c}}$ & $2.7 \pm 0.3^{\mathrm{bc}}$ & $1.6 \pm 0.5^{\mathrm{a}}$ \\
\hline OC_LAE & $3.0 \pm 0.3^{\mathrm{a}}$ & $4.2 \pm 0.6^{\mathrm{a}}$ & $2.3 \pm 1.3^{\mathrm{a}}$ & $3.5 \pm 0.7^{\mathrm{a}}$ & $1.5 \pm 0.5^{\mathrm{a}}$ & $\mathrm{ndg}^{\star *}$ \\
\hline TP_C & $5.1 \pm 0.5^{\mathrm{c}}$ & $5.5 \pm 0.5^{\mathrm{c}}$ & $4.4 \pm 0.4^{\mathrm{c}}$ & $4.9 \pm 0.3^{\mathrm{C}}$ & $3.0 \pm 0.7^{\mathrm{C}}$ & $2.1 \pm 0.7^{\mathrm{a}}$ \\
\hline TP_LAE & $4.0 \pm 0.9^{\mathrm{b}}$ & $4.7 \pm 0.7^{\mathrm{b}}$ & $3.5 \pm 0.5^{\mathrm{ab}}$ & $4.1 \pm 0.7^{\mathrm{ab}}$ & $2.3 \pm 0.8^{\mathrm{b}}$ & $1.4 \pm 0.3^{\mathrm{a}}$ \\
\hline
\end{tabular}

$518 \quad{ }^{*}$ All values are means \pm standard deviations of duplicate data from three independent experiments $(n=6)$.

519 OC: oxidized starch coating; TP: thermo-processed.

$520 * *$ *ndg, no detected growth under the limit of detection.

$521 a, b, c$ Different superscripts letters in the same column indicate significant differences $(p<0.05)$ 